\title{
A Method for the Selective Quantification of Brønsted Acid Sites on External Surfaces and in Mesopores of Hierarchical Zeolites
}

Carolin Rieg, ${ }^{[a]}$ Zheng Li, ${ }^{[a]}$ Alan Kurtz, ${ }^{\text {[a] }}$ Maximilian Schmidt, ${ }^{[a]}$ Daniel Dittmann, ${ }^{[a]}$ Michael Benz, ${ }^{[a]}$ and Michael Dyballa[a]*

[a] Institute of Technical Chemistry, University of Stuttgart, Pfaffenwaldring 55, 70569 Stuttgart, Germany

*Corresponding author, E-mail: michael.dyballa@itc.uni-stuttgart.de

\begin{tabular}{l|l}
\hline Items & Pages \\
\hline Figure S1 & S2 \\
\hline Figure S2 + S3 & S3 \\
\hline Figure S4 & S4 \\
\hline Figure S5 & S5 \\
\hline Figure S8 & S6 \\
\hline Figure S7 & S7 \\
\hline Figure S8 & S8 \\
\hline Figure S9 & S9 \\
\hline Figure S10 & S10 \\
\hline Figure S11 & S11 \\
\hline Figure S12 & S12 \\
\hline
\end{tabular}




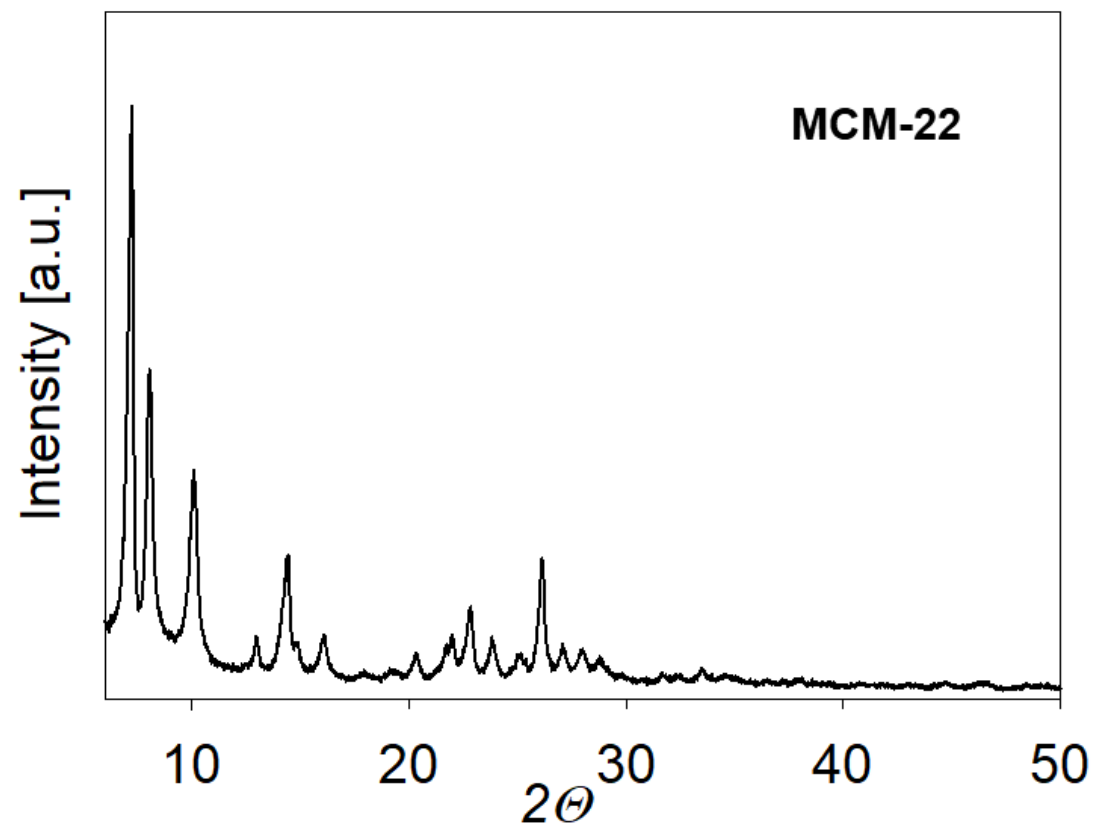

Figure S1: X-ray powder diffraction patterns of the MCM-22 zeolite under study showing reflexes of a pure MWW structure. 


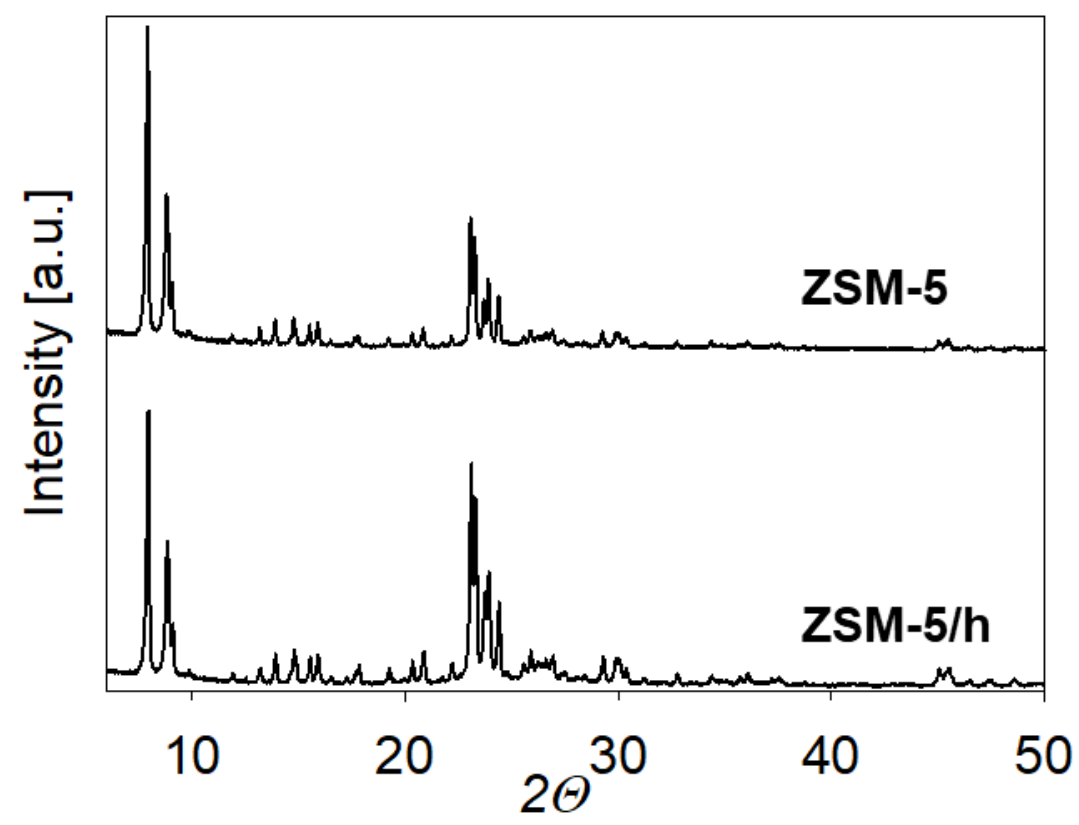

Figure S2: X-ray powder diffraction patterns of the ZSM-5 zeolite before and after (ZSM-5/h) desilication showing reflexes of a pure MFI structure.

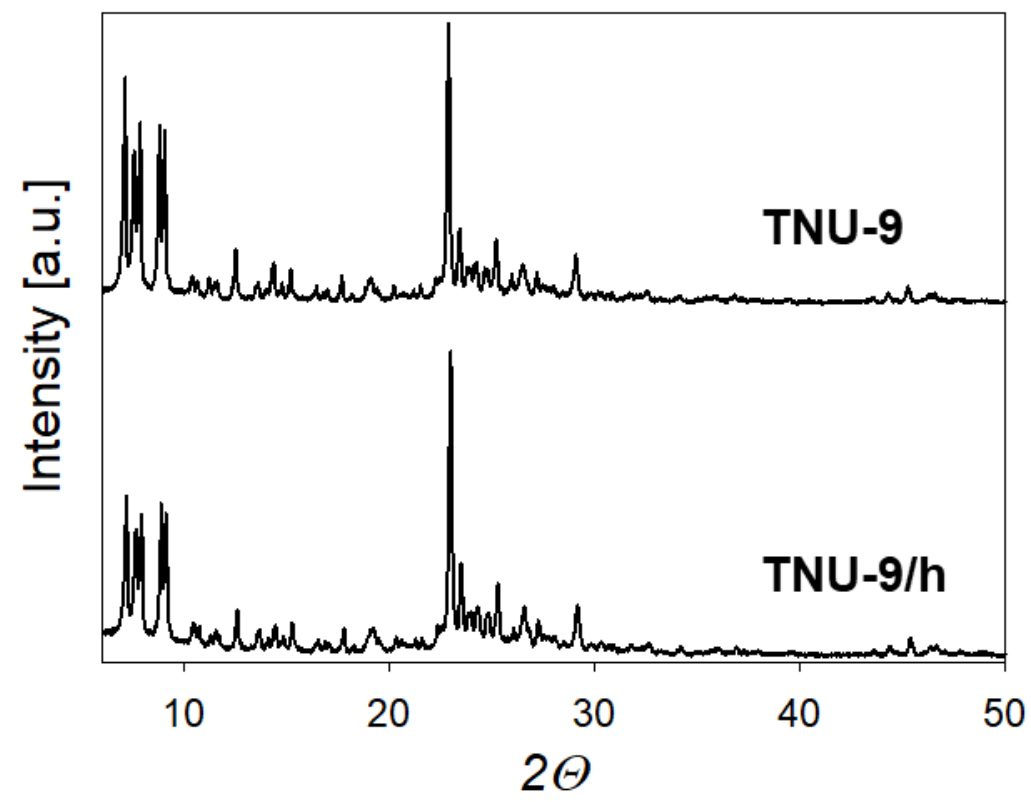

Figure S3: X-ray powder diffraction patterns of the TNU-9 zeolite before and after (TNU-9/h) desilication showing reflexes of a pure TUN structure. 

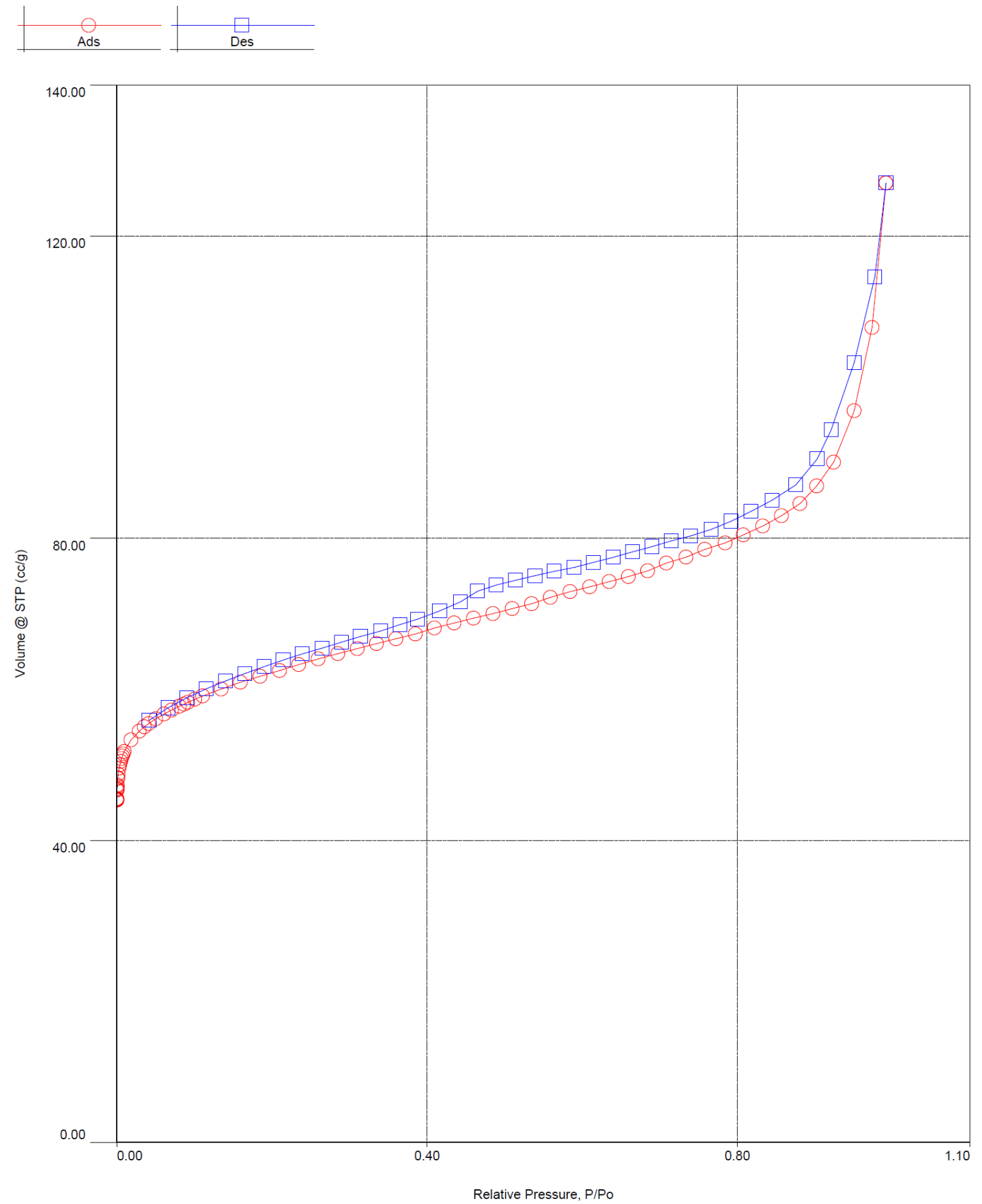

Figure S4: $\mathrm{N}_{2}-\mathrm{Physisorption}$ isotherm of $\mathrm{ZSM}-5 / \mathrm{h}$. 

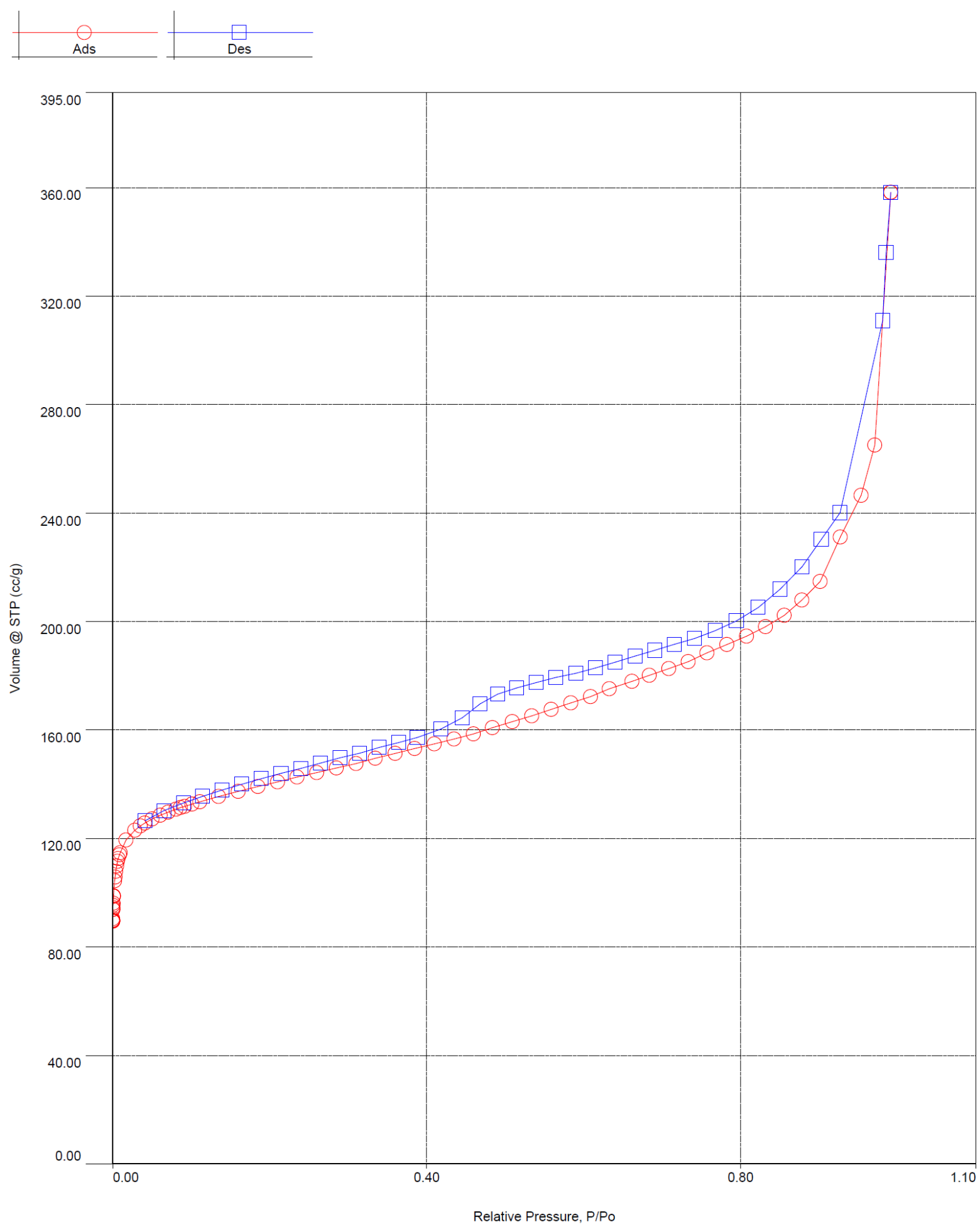

Figure S5: $\mathrm{N}_{2}-$ Physisorption isotherm of $\mathrm{TNU}-9 / \mathrm{h}$. 
${ }^{27}$ AI MAS NMR

Amorphous Si-Al (ASA)

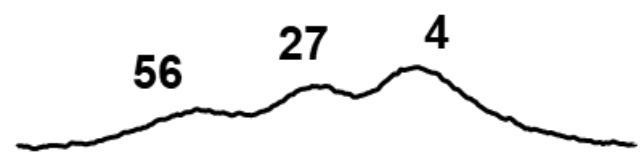

MCM-22

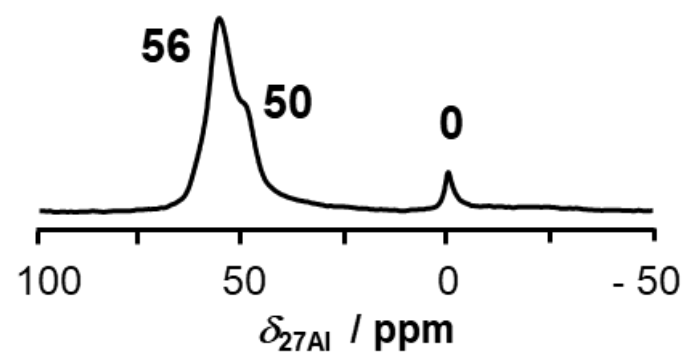

Figure S6: ${ }^{27} \mathrm{Al}$ MAS NMR spectra of fully hydrated $\mathrm{H}$-forms of ASA and MCM-22 samples. 


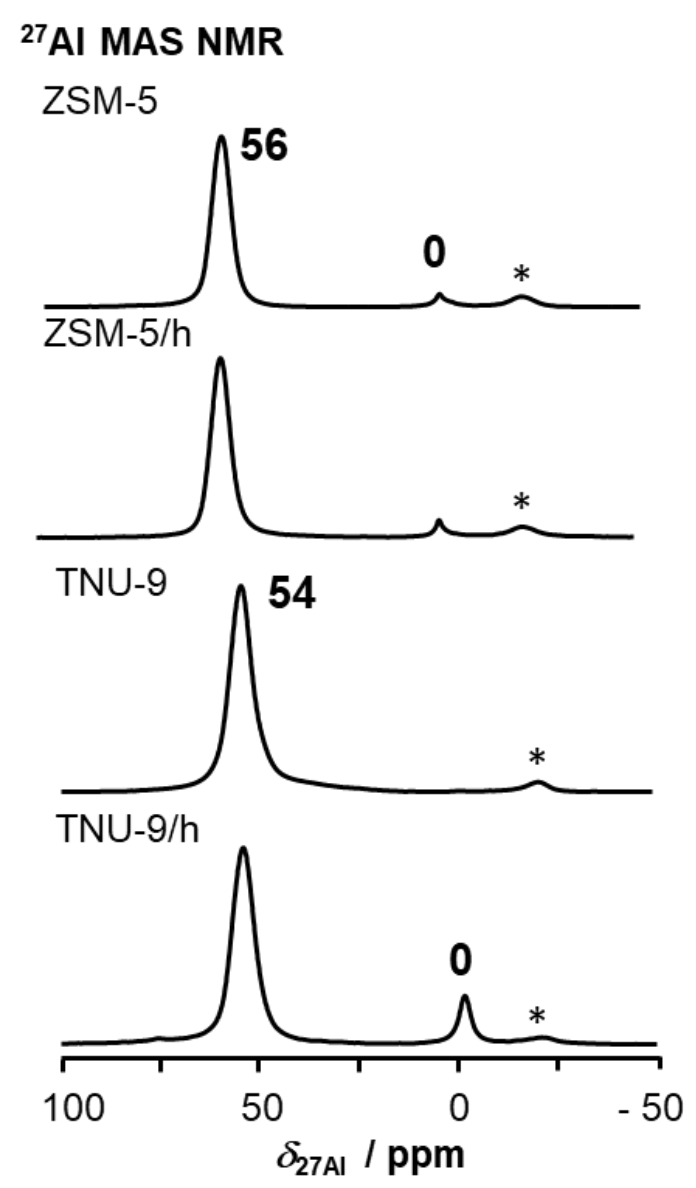

Figure S7: ${ }^{27} \mathrm{AI}$ MAS NMR spectra of fully hydrated $\mathrm{H}$-form ZSM- 5 and TNU-9 zeolites as well as of their desilicated, hierarchical counterparts ZSM-5/h and TNU-9/h below. 


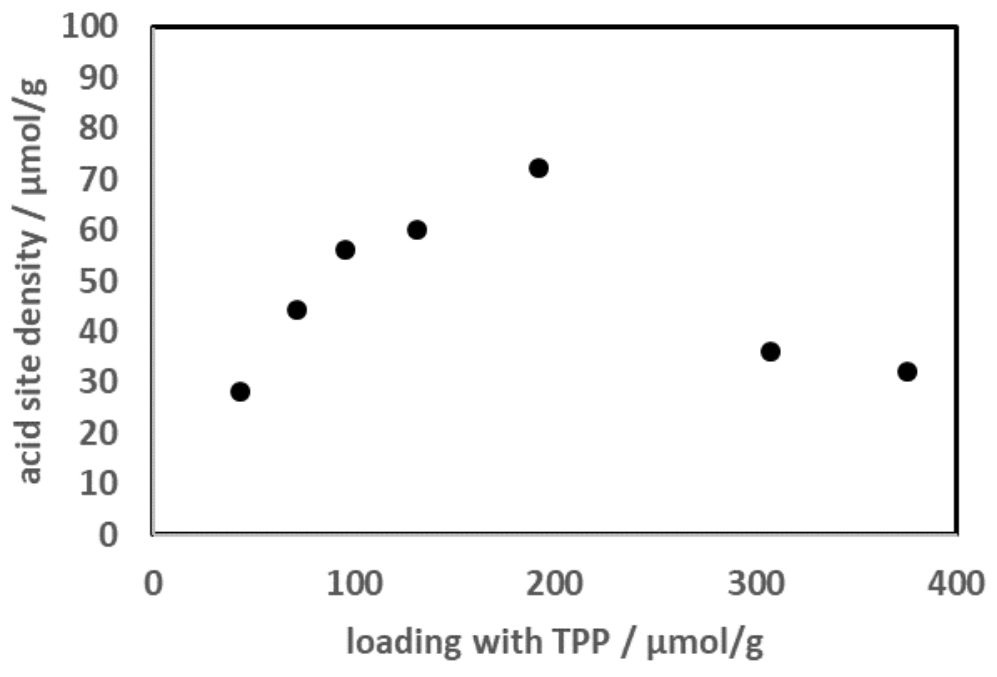

Figure S8: Values from a previous publication. Dependence of the detected Brønsted acid site density of amorphous silica-alumina on the total loading amount with triphenylphosphine (TPP). Plotted according to $\mathrm{Hu}$ and Gay, with values calculated using the published specific surface of $400 \mathrm{~m}^{2} / \mathrm{g}$ and values from Table 1 in the original publication (Hu, B.; Gay, I. D., Probing Surface Acidity by 31P Nuclear Magnetic Resonance Spectroscopy of Arylphosphines. Langmuir 1999, 15, 477-481). 


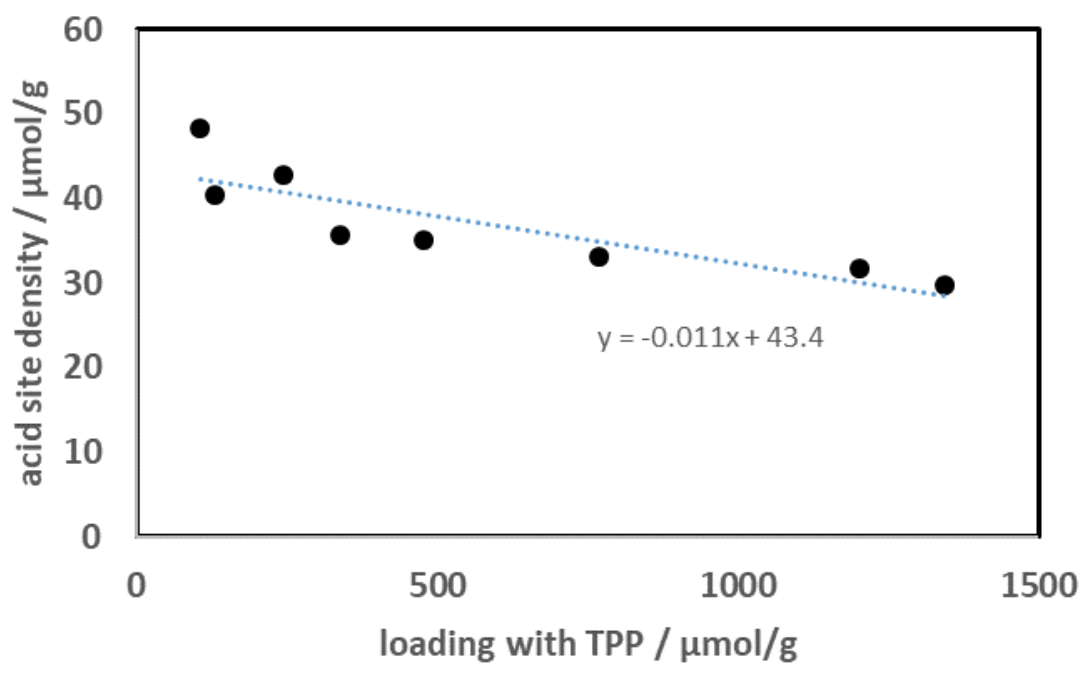

Figure 59: Dependence of quantified acid site density against the total loading quantity using triphenylphosphine (TPP). The mass of the material was not corrected for the mass of TPP. The graph has to be extrapolated until zero loading (i.e. absence of TPP), leading to an acid site density of the sample of $43.4 \mu \mathrm{mol} / \mathrm{g}$ (rounded to $43 \pm 3$ $\mu \mathrm{mol} / \mathrm{g}$ ). Comparing to the average value from mass-corrected measurements (see Figure 3 ) of $44 \pm 3 \mu \mathrm{mol} / \mathrm{g}$, this is a negligible difference of $<0.5 \%$ (not rounded values). 
${ }^{1} \mathrm{H}$ MAS NMR

MCM-22

\section{${ }^{27}$ AI MAS NMR}

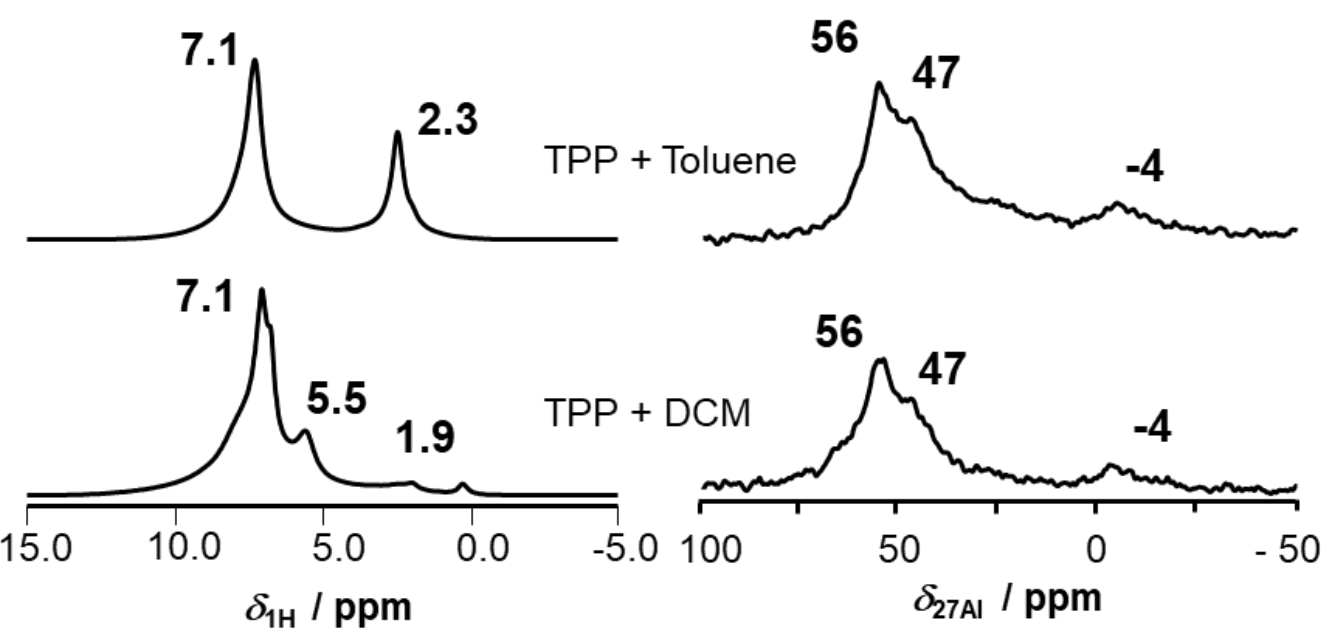

Figure S10: ${ }^{1} \mathrm{H}$ and ${ }^{27} \mathrm{Al}$ MAS NMR spectra of zeolite MCM-22 with traces of Toluene (top, ${ }^{1} \mathrm{H}$ signal of methyl at $2.3 \mathrm{ppm}$ ) and $\mathrm{DCM}$ (bottom, ${ }^{1} \mathrm{H}$ signal at $5.5 \mathrm{ppm}$ ) after incomplete desorption at $\mathrm{RT}$ under flowing, dry $\mathrm{N}_{2}$. The ${ }^{1} \mathrm{H}$ signal at $1.9 \mathrm{ppm}$ (error \pm 0.1 ppm) belongs to surface $\mathrm{Si}(\mathrm{OH})$ groups. 


\section{${ }^{27}$ AI MAS NMR}

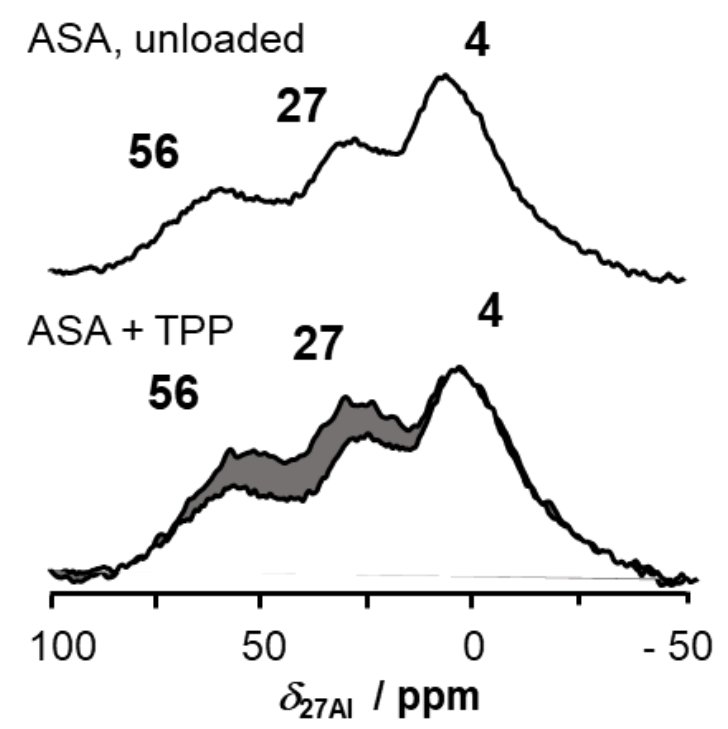

Figure S11: ${ }^{27} \mathrm{Al}$ MAS NMR spectra of dehydrated amorphous silica-alumina (ASA, top) and of ASA after loading TPP (108 $\mu \mathrm{mol} / \mathrm{g})$. Differences in ${ }^{27} \mathrm{Al}$ MAS NMR spectra indicated in grey. 
${ }^{1} \mathrm{H}$ MAS NMR
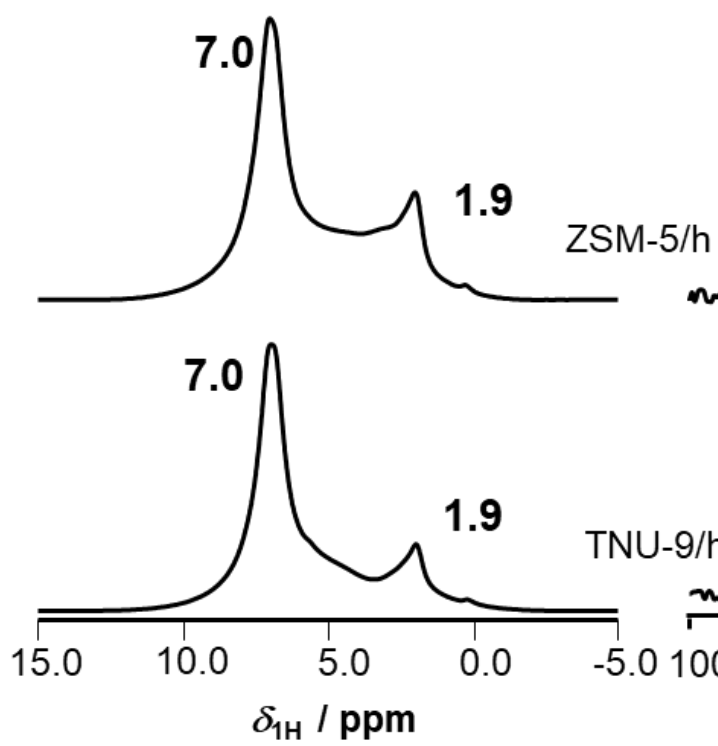

${ }^{27}$ AI MAS NMR
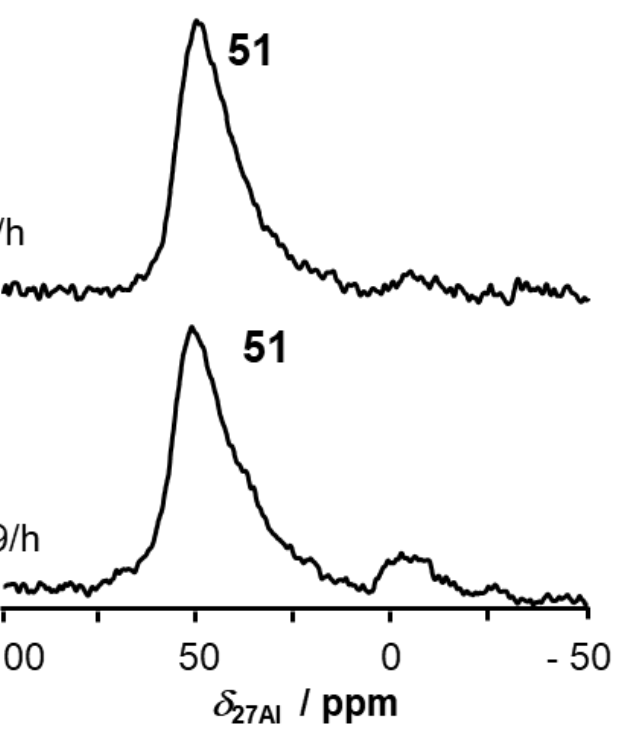

Figure S12: ${ }^{1} \mathrm{H}$ and ${ }^{27} \mathrm{Al}$ MAS NMR spectra of hierarchical zeolites $Z \mathrm{SM}-5 / \mathrm{h}$ (top) and TNU-9/h (bottom) after TPP loading verifying the binding of TPP at the acid sites and absence of solvent. 